\title{
ALTERNATIVAS PARA LA AUTOGESTIÓN DE LOS DERECHOS DE AUTOR EN EL MUNDO DIGITAL
}

\author{
Víctor Torres-Padrosa y Jaime Delgado-Mercé
}

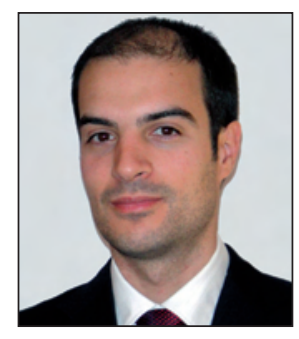

Víctor Torres-Padrosa es doctor ingeniero de telecomunicación desde 2008 por la Universitat Pompeu Fabra (UPF). Ingeniero de telecomunicación desde 2003 por la Universitat Politècnica de Catalunya (UPC). Profesor ayudante doctor en el Departamento de Arquitectura de Computadores de la UPC desde 2010. Previamente, fue profesor visitante en el Departamento de Tecnologías de la Información y las Comunicaciones de la UPF desde 2008 hasta 2010. Miembro del grupo de investigación Distributed Multimedia Applications Group (DMAG) desde 2003. Project manager de diversos proyectos de investigación europeos y nacionales en temas de comercio electrónico, gestión digital de derechos (DRM), metadatos, contenidos multimedia, seguridad y aplicaciones distribuidas, entre otros. Ha participado en la estandarización de MPEG-21 y en numerosos proyectos de investigación europeos y nacionales en el área $D R M$, multimedia, seguridad y aplicaciones distribuidas. Autor de numerosos artículos en conferencias y revistas internacionales. Revisor de las revistas IEEE multimedia, ETRI journal y El profesional de la información.

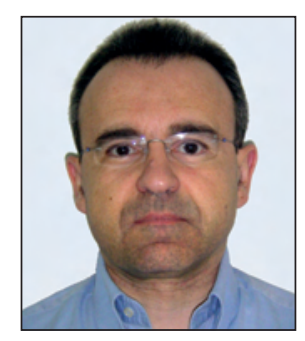

Jaime Delgado-Mercé, doctor ingeniero de telecomunicación desde 1987, es catedrático del Departamento de Arquitectura de Computadores de la Universitat Politècnica de Catalunya (UPC) desde septiembre de 2006. Previamente fue catedrático en la Universitat Pompeu Fabra, desde 1999, siendo director de los estudios de informática entre 2001 y 2004 . Director y fundador del grupo de investigación Distributed Multimedia Applications Group (DMAG). Project manager de diversos proyectos de investigación europeos y nacionales en temas de comercio electrónico, gestión digital de derechos (DRM), metadatos, contenidos multimedia, seguridad y aplicaciones distribuidas, entre otros. Editor de varios estándares internacionales y co-chair de varios grupos de estandarización. Actualmente activo en MPEG y JPEG. Evaluador y revisor para la Comisión Europea y varios ministerios españoles desde 1989. Autor de cientos de artículos y libros. Miembro del Comité de Evaluación de Enseñanzas Técnicas de la Aquib (Agència de Qualitat Universitària de les Illes Balears) desde 2006. Coordinador del máster CANS (Computer architecture, networks and systems) del Departamento de Arquitectura de Computadores de la UPC desde 2007.

Universitat Politècnica de Catalunya Jordi Girona, 1-3, Campus Nord, Módulo D6 Barcelona 08034 jaime.delgado@ac.upc.edu vtorres@ac.upc.edu

\section{Resumen}

Se analizan las diferentes alternativas de que disponen los creadores para beneficiarse de la explotación de los derechos de propiedad intelectual de sus obras. En concreto, de los derechos de autor. En primer lugar se proporciona una visión general del concepto de propiedad intelectual para seguidamente describir las posibilidades de gestión de los derechos, entre las que tenemos la gestión colectiva y la autogestión. A continuación se analiza una selección de iniciativas que permiten a los usuarios autogestionar parte de sus derechos de propiedad intelectual, bien sea para ceder libremente parte de ellos, bien sea para obtener un beneficio económico de su explotación. Finalmente, se proponen cuáles deberían ser las características de un sistema integral de la propiedad intelectual y se presentan los resultados y prototipos obtenidos por nuestro grupo.

\section{Palabras clave}

Propiedad intelectual, Derechos de autor, Gestión digital de los derechos, Licenciamiento, Gestión colectiva, Creative commons.

\section{Title: Alternatives for the self-management of author rights in the digital world}

\section{Abstract}

We analyse different alternatives that facilitate the exploitation of intellectual property. Specifically, we deal with author's rights. First we provide a general overview of the intellectual property concept and then we describe the rights management alternatives, including collective management and self management. Next, we analyse a selected set of 
initiatives that enable users to self manage their intellectual property rights, by partially transferring them or by obtaining economic benefits in exchange. We finally propose the main features for a comprehensive intellectual property system and present the results and prototypes that our research group has obtained and developed.

\section{Keywords}

Intellectual property, Author rights, Digital rights management, DRM, Licensing, Collective management, Creative commons.

Torres-Padrosa, Víctor; Delgado-Mercé, Jaime. "Alternativas para la autogestión de los derechos de autor en el mundo digital". El profesional de la información, 2011, enero-febrero, v. 20, n. 1, pp. 61-69.

DOI: 10.3145/epi.2011.ene.08

\section{Introducción}

En el mundo actual cada vez más digitalizado, los usuarios de servicios telemáticos se comportan en muchas ocasiones no sólo como consumidores de contenido digital, sino también como productores o creadores. De hecho, existen numerosas aplicaciones que facilitan que los usuarios distribuyan su contenido (textos, vídeos, imágenes y música) sin ofrecerles la posibilidad de beneficiarse de su uso por parte de terceros.

Si bien algunos portales como YouTube han empezado a remunerar a los usuarios con un número de visitas elevadas y sostenidas en el tiempo ${ }^{1}$, dicho contenido se distribuye la mayoría de veces sin ningún tipo de control y con muy pocas posibilidades de retribución para sus creadores.

En este artículo se analizan las diferentes alternativas de que disponen los creadores para beneficiarse de la explotación de los derechos de propiedad intelectual de sus obras, proponiendo y presentando nuestros avances en la creación de un sistema de gestión integral de la propiedad intelectual.

\section{Propiedad intelectual}

Es la propiedad que le corresponde a los creadores u otras entidades (autores, artistas, productores, radiodifusores, empresas, etc.), Ilamados titulares de derechos, con respecto a las "creaciones de la mente", esto es, inventos, obras literarias, artísticas y científicas, símbolos, nombres, imágenes y diseños utilizados en el comercio, entre otros.

Los derechos de la propiedad intelectual, recogidos en el artículo 27 de la Declaración universal de los derechos humanos, son el conjunto de derechos cuyo objetivo es proteger los intereses morales y materiales de los creadores sobre su propia obra o creación.

Existen principalmente dos categorías de propiedad intelectual. En primer lugar, tenemos la propiedad industrial, que incluye inventos (patentes) y marcas registradas, entre otros. En segundo lugar, tenemos el derecho de autor o copyright, que abarca obras literarias, artísticas y científicas ( $p$. ej. pinturas, fotografías, obras musicales, etc.) y obras tecnológicas, como programas de computador y bases de datos electrónicas. En el manual Principios básicos del derecho de autor y los derechos conexos editado por la Organización Mundial de la Propiedad Intelectual (WIPO/OMPI) ${ }^{2}$ puede encontrarse una lista ampliada de los tipos de obras protegidas por el derecho de autor.
Existen ciertas diferencias entre el derecho de autor y el copyright, si bien se ha dado una sucesiva convergencia entre ambos ${ }^{3,4}$. Mientras que el primero procede del derecho continental -concretamente del francés-y regula los derechos que la ley concede a los autores, el segundo proviene del derecho anglosajón y se centra en la obra, regulando aquello que puede hacerse sobre la misma. Sin embargo, en ambos casos, las legislaciones correspondientes suelen reconocer derechos tanto morales como patrimoniales. Mientras que en las legislaciones donde aplica el copyright los derechos morales suelen reducirse a que el autor pueda reivindicar la paternidad de la obra (derecho de paternidad) y a que pueda oponerse a la modificación o uso de la obra que suponga un atentado contra su honor (derecho de integridad), en el derecho de autor son más amplios. En España, donde aplica el derecho de autor, la ley de referencia es la Ley de propiedad intelectual (LPI). El artículo 14 de la LPI recoge 7 derechos morales, que incluyen, entre otros y además de los anteriores:

- el derecho a decidir si la obra ha de ser divulgada y en qué forma;

- el derecho a modificar la obra respetando los derechos adquiridos por terceros y las exigencias de protección de bienes de interés cultural; y

- el derecho a retirar la obra del comercio, por cambio de sus convicciones intelectuales o morales, previa indemnización de daños y perjuicios a los titulares de derechos de explotación.

Mientras que los derechos morales son irrenunciables e inalienables, los derechos patrimoniales pueden cederse a terceros y permiten que el titular de los derechos autorice y perciba retribución económica derivada del uso de su obra por parte de terceros. En España la $L P I$ reconoce los siguientes derechos patrimoniales, también llamados derechos de explotación:

- Reproducción: fijación directa o indirecta, provisional o permanente, por cualquier medio y en cualquier forma, de toda la obra o de parte de ella, que permita su comunicación o la obtención de copias (p. ej. grabación de una copia de una obra en soporte CD).

- Distribución: puesta a disposición del público del original o de las copias de la obra, en un soporte tangible, mediante su venta, alquiler, préstamo o de cualquier otra forma (p. ej. venta de discos musicales).

- Comunicación pública: todo acto por el cual una pluralidad de personas pueda tener acceso a la obra sin previa distribución de ejemplares a cada una de ellas, excluyen- 
do comunicaciones de ámbito doméstico. Incluye, entre otros, la interpretación o ejecución públicas (p. ej. concierto), la radiodifusión o comunicación al público (p. ej. retransmisión de una obra de teatro por televisión) y la puesta a disposición del público (p. ej. ofrecer una obra en formato digital para descarga en un computador).

- Transformación: traducción, adaptación (p. ej. de novela a película) y cualquier otra modificación en su forma de la que se derive una obra diferente.

Existen otro tipo de derechos, los llamados derechos conexos, que aplican a artistas, intérpretes, ejecutantes, productores de fonogramas y organismos de radiodifusión, que les son conferidos en virtud de su intervención creativa en la obra o de su contribución a la puesta a disposición al público o en el control de uso y transmisión de la misma. La LPI reconoce también derechos morales y patrimoniales dentro de este ámbito.

Los derechos patrimoniales, tanto los de autor como los conexos, se pueden subdividir, a su vez, en derechos exclusivos y de remuneración. Mientras que los exclusivos son aquellos que pueden ser autorizados o prohibidos por su titular (p. ej. el autor de una novela puede autorizar o prohibir su traducción a otro idioma o su adaptación para un guión, o ceder dicho derecho a un tercero, como una editorial), los de remuneración permiten al titular percibir retribución por la distribución o comunicación pública de la obra (p. ej. tanto los autores como los artistas participantes en una obra audiovisual tienen reconocido el derecho a percibir remuneración por la retransmisión de la obra en un evento público).

El derecho de autor depende de las leyes aplicables en cada jurisdicción. Los países pueden adherirse a convenios y convenciones de carácter general, como el Convenio de Berna ${ }^{5}$ o la Convención de Roma ${ }^{6}$, previa promulgación, en caso necesario, de nuevas leyes que aseguren su cumplimiento. En el caso de España, como ya se ha comentado, la legislación aplicable es la LPI. Existen algunos organismos internacionales, como la citada $\mathrm{OMPl}^{7}$, encargados de promocionar la adopción de estas convenciones y proporcionar soporte a los países no adheridos para adoptarlas en sus legislaciones correspondientes.

En España la LPI impone la obligatoriedad de la gestión colectiva para los derechos de remuneración (artículos 90, 108, 109,116 y 122 de la $L P I$ ) y para el derecho exclusivo de autorizar la retransmisión por cable (artículo 20 de la $L P I)$. Mientras que la segunda imposición obedece a la transposición de una directiva europea ${ }^{8}$, la primera es una restricción impuesta por la legislación española. Por lo tanto, parte de los derechos pueden ser de gestión colectiva obligatoria, dependiendo de la legislación aplicable, lo que significa que el titular de los derechos sólo podrá optar a los mismos mediante su afiliación a dichas sociedades. Por otra parte, los titulares de derechos, si lo desean, pueden delegar sus derechos de gestión colectiva no obligatoria en sociedades de gestión de derechos.

\section{Gestión de los derechos de autor}

Una vez descrito el concepto de derechos de autor, pasamos a analizar de qué alternativas disponen los titulares de los mismos para poder gestionar sus derechos patrimoniales (p. ej. percibir las contraprestaciones económicas correspondientes por la venta de las obras) y para poder asegurar que se respetan sus derechos morales.

\section{Gestión colectiva}

Una primera alternativa consiste en la afiliación a una entidad de gestión colectiva cuyo objeto es "la gestión de derechos de explotación u otros de carácter patrimonial, por cuenta y en interés de varios autores u otros titulares de derechos de propiedad intelectual". En España dichas sociedades deben contar con la autorización del Ministerio de Cultura.

La asociación es voluntaria y los socios les transfieren la capacidad de licenciar el uso de sus obras de acuerdo con unas tarifas estipuladas por estas sociedades, que son negociadas con cada colectivo (p. ej. hostelería).

Dichas sociedades disponen de un conjunto de obras de sus asociados, conocidas como repertorio, para las que licencian su uso, persiguen su uso ilícito (no licenciado), recaudan las tasas de licenciamiento y las reparten entre sus asociados de forma proporcional y equitativa, en función del uso de cada obra. Existen igualmente acuerdos de reciprocidad suscritos entre entidades de gestión de diferentes países en aras de asegurar un óptimo control del uso de sus repertorios a nivel internacional.

Una de las principales ventajas para los autores al optar por esta alternativa reside en la amplia experiencia e infraestructura de dichas sociedades para recaudar y perseguir el uso ilícito, tarea que no está al alcance de la mayoría de sus asociados. Por otra parte, algunos asociados denuncian que el reparto, basado en estimaciones del uso del repertorio, no se realiza siempre de manera correcta o equitativa ${ }^{9}$ o no permite que se beneficien pequeños autores cuya obra no es ampliamente conocida y se usa a escala reducida ${ }^{10}$.

Para optar por la gestión colectiva el titular de derechos debe asociarse a la sociedad de gestión de derechos de su especialidad (autores, artistas, productores, etc.) y registrar las obras que desea que formen parte del repertorio de dichas sociedades ${ }^{11,12}$.

\section{Autogestión}

Una segunda alternativa para la gestión de los derechos de autor es lo que denominamos autogestión. En este caso el titular de derechos no se asocia a una entidad de gestión de derechos, sino que decide gestionar de forma personal o a través de otros medios sus derechos de autor.

Las vías para ejercer la autogestión son muy diversas y pueden incluir: la réplica de las funciones de una entidad de gestión de derechos, la suscripción de acuerdos de comercialización a título personal con portales de promoción y distribución de contenido o la cesión de algunos o todos los derechos de autor sin contraprestación económica, pero con otras condiciones, como analizaremos en secciones posteriores.

Tanto en la gestión colectiva como en la autogestión los titulares de derechos deberán ser capaces de demostrar que son los creadores de la obra que se debe gestionar. Para este 
fin existen, en el caso de gestión colectiva, mecanismos propios de las sociedades para el registro de obras. En el caso de la autogestión, como veremos más adelante, se requerirá de lo que se suele conocer como prueba de autoría.

\section{Aplicabilidad del derecho de autor}

En la mayoría de países, incluyendo España, cualquier obra queda bajo el amparo del derecho de autor desde el momento en que se crea. Sin bien no es imprescindible, es importante disponer de una prueba de autoría que reconozca al autor original como el creador de la obra. Dicha prueba será útil para poder asegurar el ejercicio de los derechos conferidos por el derecho de autor en caso de litigio. La inclusión del símbolo (c) en la obra o acompañando a la misma es una manera válida para declarar la existencia del derecho de autor, pero no se puede considerar una prueba fehaciente de autoría, por lo que se han desarrollado otros mecanismos de carácter no obligatorio como los registros de propiedad intelectual.

\section{Iniciativas existentes}

\section{Registros de propiedad intelectual}

Los registros de propiedad intelectual proporcionan un mecanismo oficial para el registro y prueba de autoría de contenido tanto analógico como digital. Habitualmente dependen de los gobiernos de los países o están regulados por las legislaciones correspondientes.

Si bien el registro del contenido, también llamado inscripción registral, no es obligatorio a efectos de que una obra quede sujeta al derecho de autor, es útil porque proporciona protección de los derechos de propiedad intelectual, en tanto que constituye una prueba cualificada de la existencia de los derechos inscritos y de a quién pertenecen. En cualquier caso no suponen una prueba definitiva, pues pueden producirse registros fraudulentos.

Algunos registros de propiedad intelectual ofrecen facilidades de registro en línea, como en el caso de los registros de España ${ }^{13}$ y EUA ${ }^{14}$, lo que evita a los autores la ardua tarea de realizar un registro tradicional de forma presencial.

A pesar de ser la vía oficial para registrar contenido, presentan una serie de características que dificultan un uso más extendido de los mismos. En primer lugar, la imposibilidad de interactuar con otras aplicaciones mediante interfaces de programación de aplicación $(A P I)$ impide que se construyan aplicaciones integradoras que hagan uso de estos registros (p. ej. registro automático de las fotografías colgadas por los usuarios en portales como Flickr, Picasa o Panoramio, previo pago de las tasas correspondientes y previa autenticación del usuario). Otras de las funciones deseables serían la posibilidad para los autores de determinar otros esquemas de licenciamiento distintos del "todos los derechos reservados" que se asume de facto, capacidades de búsqueda potentes e incluso determinar opciones de comercialización del contenido.

\section{Licenciamiento Creative Commons}

Creative Commons $(C C)^{15}$ es una organización sin ánimo de lucro que proporciona una serie de licencias que pueden utilizarse por parte de los titulares de derechos para deter- minar que sobre su contenido no están "todos los derechos reservados", sino únicamente una parte de ellos. Las licencias CC han sido diseñadas para ser compatibles con las reglas del derecho de autor y del copyright.

Así, los titulares de derechos seleccionan la licencia de su interés y la vinculan a su contenido, habitualmente mediante un identificativo que indica el tipo de licencia que le aplica y que en el caso de las webs contiene un enlace hacia la interpretación y el texto íntegro de la licencia.

Las licencias CC suelen utilizarse para permitir que otros usuarios puedan utilizar y distribuir un contenido de forma libre, sin obligación de pagar por su uso, pero con posibles restricciones adicionales como el reconocimiento de autoría (by), la limitación a que el uso sea de tipo no comercial (nc), la prohibición de crear obras derivadas de la original (nd) y la obligación de compartir cualquier obra derivada bajo el mismo tipo de licencia que aplica a la obra original (share alike, sa). Los tipos de licencias existentes resultan de la combinación de las restricciones anteriores (by, by-nc, by$n d, b y-s a, b y-n c-n d, b y-n c-s a)^{16}$.

Es importante destacar la necesidad de que los usuarios que van a hacer uso del contenido, a los que nos referiremos como consumidores, sean capaces de demostrar cuál es la licencia aplicable a un contenido. Como veremos, CC presenta algunos inconvenientes en este sentido.

Supongamos el siguiente caso: Un editor utiliza imágenes licenciadas mediante CC para ilustrar una revista online. Supongamos que obtiene una imagen de Flickr, que permite que los usuarios que cuelgan fotografías les asocien licencias CC, y que dicha imagen tiene asociada una licencia CC que permite a otros copiar, distribuir, mostrar e interpretar la obra y obras derivadas sin contraprestación económica pero con reconocimiento de autoría (modelo $\mathrm{CC}$ by ${ }^{16}$ ). Posteriormente el titular de derechos modifica la licencia aplicable a CC by- $n c^{16}$, equivalente al anterior, pero que prohíbe hacer un uso comercial de la obra. ¿Qué ocurre entonces? ¿Qué licencia debe respetar el editor? De acuerdo con el modelo CC, dependerá de la licencia aplicable en el momento en que el editor accedió a la fotografía. Si fue en un instante anterior al cambio, podrá utilizar de forma perpetua la fotografía sin contraprestación económica. Si fue posterior, no podrá hacer un uso comercial de la misma.

El caso anterior nos plantea la siguiente pregunta: ¿cómo demuestra el editor el tipo de licencia aplicable al contenido? Esta pregunta no tiene solución en CC, pues las licencias son genéricas y no permiten vincular los derechos y condiciones a consumidores como el editor.

Varios análisis recogen las debilidades que presenta el uso de licencias $\mathrm{CC}^{17,18}$.

A continuación nos centraremos en las dificultades a las que se enfrentan los autores que no quieren ceder libremente sus derechos de autor y los consumidores de obras bajo licencia CC:

1) Dificultad de los titulares de derechos para determinar cómo quieren comercializar su contenido indicando contraprestaciones económicas dependientes del uso que se haga del contenido. 
2) Falta de protección para los titulares de derechos debido a la duración de la licencia. Las licencias CC confieren derechos perpetuos (por la duración del derecho de autor). Cualquier cambio posterior por parte del titular de derechos no aplicará a aquellos que accedieron al contenido antes del cambio.

3) Falta de protección para los consumidores, pues deben ser capaces de demostrar qué licencia aplicaba cuando accedieron al contenido.

Respecto al primer problema CC ha definido la variante CCPlus $(\mathrm{CC}+)^{19}$, que consiste en una licencia CC no comercial a la que se le añade un enlace a un sitio especializado donde se pueden adquirir derechos específicos, o una manera de contactar con el titular de derechos, con quien se podrá negociar directamente. Un claro ejemplo de sitio especializado es el portal Getty Images ${ }^{20}$.

Por lo que se refiere al tercer problema, existen algunas iniciativas para ámbitos específicos, como ImageStamper ${ }^{21}$ para imágenes. Esta herramienta en línea genera y almacena una huella temporal firmada digitalmente que contiene la imagen, la licencia aplicable y la fecha.

Veremos cómo las dificultades anteriores, incluyendo la segunda, que no tiene solución en CC, pueden ser resueltas mediante otras alternativas.

Por último cabe destacar que el uso de licencias CC es incompatible con la gestión colectiva, pues CC implica la cesión gratuita de algunos derechos de autor, lo que no tiene cabida dentro de la gestión colectiva. Por otra parte es presumible que CC no podrá ser aplicado cuando deban satisfacerse derechos de remuneración para los participantes (p. ej. autores, artistas) en la obra (p. ej. obra audiovisual), puesto que CC confiere derechos (p. ej. reproducción, distribución y comunicación pública) por el plazo de protección de los derechos de propiedad intelectual y a título gratuito.

\section{Safe creative}

Safe creative $^{22}$ es un registro de propiedad intelectual gratuito, abierto e independiente, gestionado de forma privada. Como registro proporciona a los autores pruebas de autoría válidas para usar en caso de litigio, para lo que utilizan técnicas de firma digital y un servicio externo de sellado de tiempo homologado por el Ministerio de Industria, Turismo y Comercio (Mityc) de España.

Una de las principales ventajas de Safe creative frente a otros registros de propiedad intelectual reside en la posibilidad de determinar el tipo de licencia que aplica a una obra. En concreto, se ofrecen plantillas predeterminadas para licencias perfectamente establecidas como $\mathrm{CC}$ y $\mathrm{GNU}^{23}$. Por otra parte, se permite que el usuario proporcione su propio texto para otras opciones más personalizadas, lo que supone de entrada una dificultad para el usuario. El tipo de licencia para una obra se puede cambiar en cualquier momento por parte del titular de derechos, quien tiene acceso al historial de cambios realizados.

Safe creative soluciona el tercer problema identificado para CC (ver sección "Licenciamiento Creative commons") proporcionando a los consumidores un documento firmado digitalmente donde se hace constar el tipo de licencia apli- cable al contenido en la fecha en que se solicita. No da certificados para fechas anteriores a la de la petición.

Por último cabe destacar que Safe creative ofrece una API para que terceros puedan utilizar sus servicios desde sus propias aplicaciones, como es el caso de Jamendo ${ }^{24}$, plataforma de publicación y descarga de música libre. Jamendo brinda a sus usuarios las facilidades de registro de sus obras en Safe creative desde su propio portal, funcionalidad que destacábamos como deseable para los registros oficiales de propiedad intelectual.

El registro de obras en Safe creative es incompatible con la gestión colectiva siempre que se utilicen licencias CC o GNU en los términos en que se ha descrito en la sección anterior. En caso de optar por un registro declarando "todos los derechos reservados" sería compatible y proporcionaría redundancia al registro efectuado en las sociedades de gestión de derechos.

\section{Portales de licenciamiento}

Existen algunos portales web especializados en el licenciamiento de contenido para usos principalmente profesionales. Es el caso de YouLicense ${ }^{25}$ y Getty Images $^{20}$, entre otros. Mientras que el primero se centra en el licenciamiento de música, el segundo trata principalmente con imágenes.

En ambos portales el consumidor interesado puede realizar búsquedas especializadas de contenido y consultar las condiciones de licenciamiento. Tanto YouLicense como Getty Images ofrecen dos esquemas. El primero de ellos, muy parecido en ambos, permite al titular de derechos definir diferentes importes a satisfacer en función del uso de la obra (p. ej. uso no exclusivo en España durante un mes para un anuncio de televisión). La segunda variante de YouLicense permite que el consumidor haga ofertas al titular de derechos, mientras que en Getty Images consiste en un pago por la imagen dependiente de la resolución pero independiente de su uso.

Si bien la opción más natural para el uso de estos portales encajaría dentro de la autogestión de derechos, su uso no es incompatible con la gestión colectiva, en cuyo caso se deberían satisfacer las tasas de las sociedades de gestión de derechos.

\section{Funcionalidad deseable en nuevas plataformas de licenciamiento}

En esta sección proponemos cuál debería ser la funcionalidad de una plataforma de registro y comercialización de contenido que podría configurarse como un sistema integral de la propiedad intelectual.

En primer lugar necesitamos que actúe como registro de propiedad intelectual. Con tal fin proponemos representar las obras registradas mediante el lenguaje $\mathrm{xml}$ firmado digitalmente ${ }^{26}$, de manera que puedan utilizarse como pruebas fehacientes de registro. Existen dos alternativas en este sentido. La primera consiste en utilizar la firma digital del autor de la obra, para lo que será necesario hacer uso de certificados digitales X.509 emitidos por una autoridad de certificación de confianza. La segunda consiste en utilizar una firma de la propia plataforma de registro, en cuyo caso 
el nivel de confianza residirá en los procesos de seguridad implementados internamente por la misma, auditorías de seguridad y/o uso de servicios reconocidos de sellado de tiempo. La combinación de ambas alternativas proporcionaría un resultado óptimo en términos de prueba de autoría, si bien siempre podrían darse casos de registro deliberado de obras cuya autoría no corresponde al declarante, que podrían tratarse de forma automática por comparación con repositorios de información, o semiautomática por denuncia de otros usuarios.

Otra característica que consideramos relevante es la posibilidad de comercializar el contenido registrado. En este sentido proponemos que la propia plataforma actúe como punto de venta. En el momento del registro o en un instante posterior el autor podrá determinar mediante ofertas qué derechos pone a la venta y si requiere o no contraprestación económica. A fin de asegurar una buena cobertura de distintos modelos de negocio, por una parte proponemos adoptar los derechos definidos en el estándar MPEG-21 Media value chain ontology $(\mathrm{MVCO})^{27}$, que abarcan el proceso de derivación de obras y otros derechos recogidos en la Ley de propiedad intelectual como: adaptar, instanciar, copiar, distribuir, producir, comunicar públicamente y sincronizar. Por otra parte deben considerarse también aquellos derechos relacionados con el consumo y fruición: reproducir, embeber, extraer, disminuir, mejorar, etc., definidos en el estándar MPEG-21 Rights expression language $(R E L)^{28}$. Asimismo, es necesario permitir definir condiciones que aplican a los derechos anteriores. MPEG-21 REL define algunas posibilidades como intervalos de tiempo, cantidad y tipo de pago, territorio y número de veces que puede ejercerse el derecho. Sin embargo en algunas aplicaciones puede ser relevante incluir otras condiciones como las utilizadas en Creative commons (atribución, no comercial, etc.), las utilizadas habitualmente en la suscripción de contratos (exclusividad, territorio excluido) e incluso la posibilidad de especificar que el autor perciba un porcentaje de los ingresos generados por las obras derivadas.

Así, por una parte, tendremos las ofertas publicadas por los autores, que consistirán en conjuntos de derechos y condiciones aplicables al uso de un contenido. Dichas ofertas deberán configurarse mediante una interfaz sencilla e intuitiva, haciendo uso de plantillas predeterminadas para los usos más comunes. Una vez configuradas sería deseable obtener el texto legal equivalente. Por otra parte cuando un consumidor acepte una oferta se formalizará dicha adquisición mediante lo que llamamos licencia. En este caso el concepto de licencia es ligeramente diferente al caso CC. Una licencia será una prueba conforme un consumidor ha aceptado una oferta, por lo que vinculará unívocamente los derechos y condiciones que contiene una oferta para un cierto contenido con el consumidor. Es por ello que se requiere que los usuarios consumidores estén registrados en el sistema. Una licencia se puede expresar mediante un lenguaje de expresión de derechos, como MPEG-21 REL ${ }^{28}$, basado en $\mathrm{xml}$, y puede estar firmada digitalmente, por lo que puede constituir una prueba fehaciente para los consumidores.

El esquema oferta-licencia permite salvar las dificultades planteadas para CC, pues la licencia contiene los derechos y condiciones de uso que acepta el consumidor, que pueden estar restringidos a un intervalo de tiempo limitado, evitando licenciamientos indefinidos. El autor podrá modificar en cualquier momento sus ofertas, pero nunca afectará a aquellas licencias que hayan sido adquiridas previamente mientras sigan siendo válidas.

Otra funcionalidad avanzada consiste en generar ofertas a conjuntos limitados de usuarios (p. ej. sólo los clientes habituales pueden adquirir una licencia en condiciones preferentes). Para ello basta con que el autor sea capaz de identificarlos en el sistema y permitir configurar una oferta restringida en términos de clientes potenciales.

Esta plataforma sería compatible tanto con la autogestión de contenido como con la gestión colectiva. En el último caso, sin embargo, debe tenerse en cuenta que se deberán satisfacer las tasas correspondientes a las sociedades de gestión de derechos. Como no es obligatorio que el repertorio manejado por las sociedades de gestión de derechos se haga público, el cómputo de las tasas a satisfacer a dichas sociedades únicamente puede gestionarse de forma automática si el autor declara que su obra está sujeta a gestión colectiva en el caso de derechos exclusivos. Por lo que se refiere a los derechos de remuneración, el titular de los derechos podría establecer si existen terceros que puedan exigir dichos derechos, a fin de informar a los consumidores del contenido e incluso llegar a comunicarlo a las sociedades de gestión de derechos correspondientes.

\section{Desarrollos y resultados obtenidos}

El grupo de investigación $D M A G^{29}$ ha construido dos prototipos de sistemas de registro y comercialización de contenido que se encuentran actualmente en funcionamiento.

La primera plataforma se ha desarrollado en el proyecto Musiteca $^{30}$, que tiene como objetivo crear herramientas para que asociaciones musicales puedan explotar contenidos musicales y distribuirlos de forma segura, catalogarlos de forma automática y sugerir contenidos similares. Con tal fin se ha construido una plataforma como la descrita en la sección anterior, donde los usuarios pueden registrar y comercializar su contenido. Dicha plataforma es accesible mediante un portal web $^{30}$.

En este caso, una vez adquirida la licencia de interés los consumidores deben acceder al contenido licenciado desde una sección específica del portal llamada "Mis objetos comprados", desde donde se lanza un reproductor integrado en el propio navegador web, basado en tecnología ActiveX, como se aprecia en la figura 1 . Dicho reproductor se encarga de controlar el acceso al contenido, habilitándolo solamente a aquellos usuarios que dispongan de una licencia válida. Se trata, pues, de una solución de tipo gestión digital de los derechos, más conocida por digital rights management (DRM), pues el contenido no se le facilita sin protección al usuario.

La segunda plataforma, llamada Intellectual property operating system - Digital shadow (IPOS-DS), se ha desarroIlado para la empresa NetPortedltems ${ }^{31}$ y actualmente se encuentra en fase de preexplotación. Un versión inicial de dicho prototipo fue presentada en el Developer's Track de la conferencia World Wide Web 200932. En este caso, IPOS-DS 


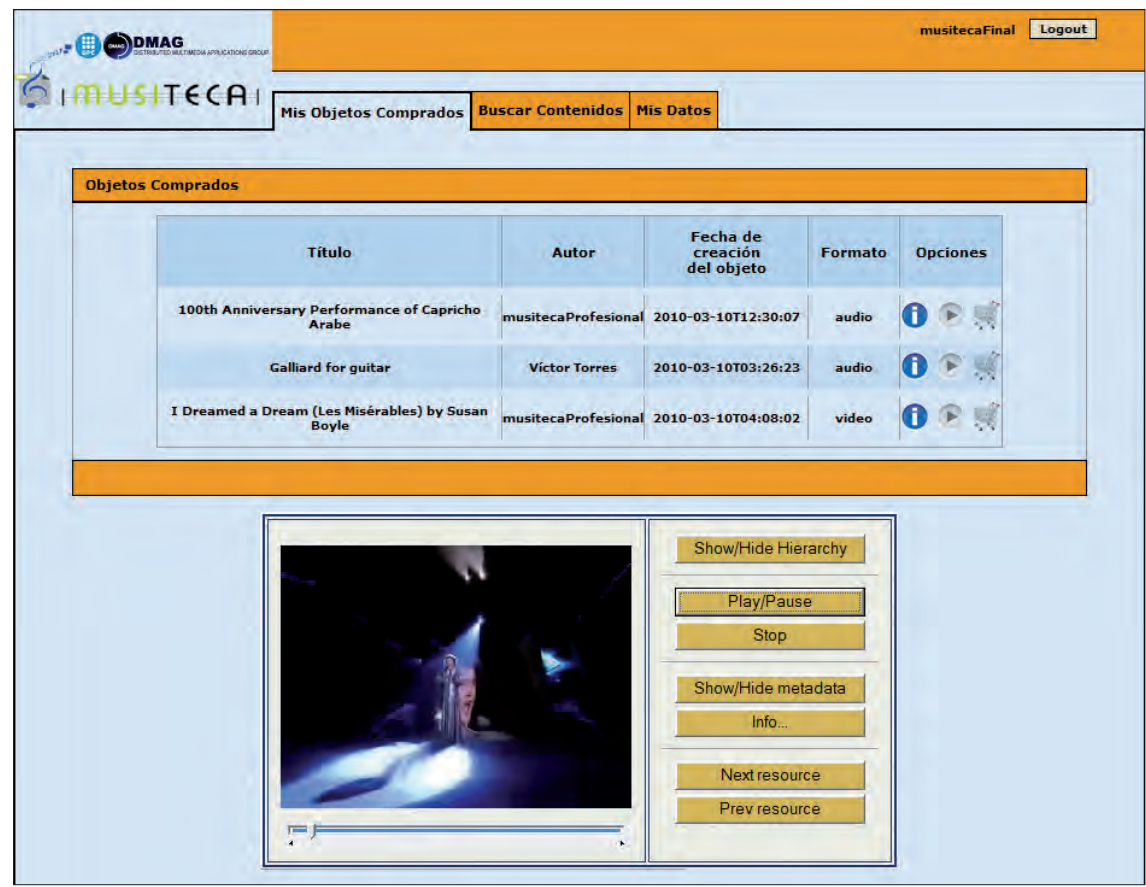

Plataforma desarrollada en el proyecto Musiteca

consiste en un portal web específico que interactúa con una arquitectura de servicios web ${ }^{33}$ propia del $D M A G^{29}$.

En IPOS-DS, de manera similar al caso anterior, el acceso al contenido licenciado se efectúa mediante una aplicación basada en tecnología java web start ${ }^{34}$ que se lanza desde el portal web. Dicha aplicación, como en el caso anterior, también comprueba la existencia de una licencia válida para el consumidor, pero en este caso le muestra a éste el contenido sin ningún tipo de protección, como se aprecia en la figura 2. Este modelo está pensado para usos profesionales en que es necesario disponer del archivo digital original para su uso o para generar una obra derivada. IPOS-DS es la única plataforma que actualmente soporta el registro de obras derivadas vinculándolas a las originales y permitiendo su trazabilidad hasta el origen, con lo que se consigue de forma implícita el reconocimiento de la autoría de todos los actores involucrados en la evolución de la obra (p. ej. creador, adaptador, instanciador y productor). También es la única plataforma que gestiona y permite que los autores perciban un porcentaje predefinido de los ingresos generados por obras derivadas, asegurando que la explotación comercial de las mismas beneficiará al autor de la obra original.

Tanto la plataforma de Musiteca como IPOS-DS controlan el licenciamiento y el acceso al contenido, proporcionando al autor información detallada de las operaciones realizadas.

Algunos aspectos de los propuestos en la sección anterior que todavía no han sido abordados son los siguientes: 1) Licenciamiento de tipo CC o GNU, aunque sí permiten especificar ofertas sin contraprestación económica; 2) Confi- guración de plantillas predeterminadas para las ofertas; 3) Autenticación de usuario basada en certificados X.509; 4) Generación automática integrada del texto legal equivalente, si bien sí se han desarrollado prototipos; 5) Comunicación a las sociedades de gestión de derechos de las transacciones en que intervengan derechos de remuneración o exclusivos transferidos.

\section{Conclusiones}

Todavía son muchos los usuarios que comparten sus obras a través de internet sin tener en cuenta que pueden llegar a ser explotadas comercialmente por terceros. Por otra parte en los últimos años ha ido surgiendo un conjunto de portales y servicios que les proporcionan servicios relacionados con la propiedad intelectual.

En este artículo hemos analizado algunas de las alternativas más relevantes que permiten a los titulares de derechos velar por sus derechos o incluso cederlos de forma gratuita. Para ello hemos planteado como alternativas la gestión colectiva y la autogestión de los derechos. Mientras que la gestión colectiva simplifica la labor del usuario en términos de recaudación de sus derechos, también es cierto que el reparto suele suscitar controversia.

Igualmente hemos visto como para cierto tipo de derechos de remuneración, la Ley de propiedad intelectual obliga a optar por esta alternativa. La autogestión, a su vez, permite un mayor control por parte del autor de la manera en que comercializa su contenido y de su recaudación, a cambio, en principio, de una mayor dificultad recaudatoria. Dentro de la autogestión también hemos planteado la posibilidad de ceder libremente parte de los derechos de autor mediante licencias como Creative commons, ilustrando las dificultades que comporta tanto para el autor como para el consumidor del contenido.

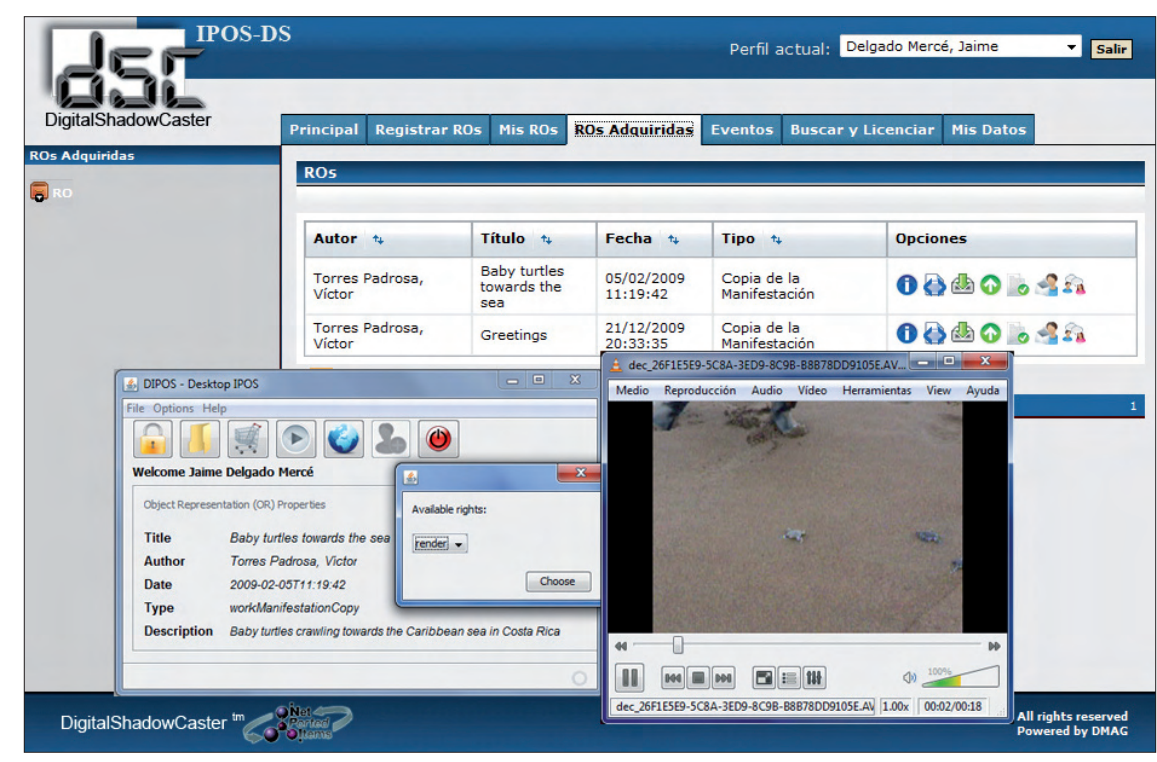

Plataforma IPOS-DS 
En nuestra opinión en los próximos años la tendencia será proporcionar servicios de registro y comercialización de contenido integrados. En este sentido hemos propuesto cuáles son las características de un sistema de gestión integral de la propiedad intelectual, que pasan por proporcionar la representación del contenido basada en estándares, la firma digital del mismo por parte del usuario y la plataforma y su sellado de tiempo, la definición y modificación de ofertas por parte del creador, la emisión de licencias vinculadas al cliente y contenido adquirido, la utilización de estándares también para la expresión de los derechos y condiciones aplicables y la interacción con otros sistemas mediante apis.

Igualmente hemos presentado los resultados a los que hemos llegado en proyectos de investigación y transferencia de tecnología. Nuestra propuesta permite que los autores o titulares de derechos se beneficien de las ventajas de la autogestión de su contenido, sin necesidad de renunciar al apoyo de la gestión colectiva. En lo que se refiere a su explotación podemos plantear tanto una gestión de dicho sistema por parte de una empresa privada, como la adopción del mismo por entidades de gestión de derechos con el fin de complementar su oferta de servicios.

\section{Agradecimientos}

Parte del trabajo presentado ha sido cofinanciado por el Ministerio de Industria, Turismo y Comercio (Mityc), mediante el proyecto Musiteca (TSI-020501-2008-117), por el Ministerio de Ciencia e Innovación (Micin), mediante el proyecto Multimedia Content Management Lyfe-Cycle (MCMLC) (TEC2008-06692-C02-01) y por la empresa NetPortedltems $S L$.

\section{Referencias}

1. Programa de socios de YouTube http://www.youtube.com/partners

2. Organización Mundial de la Propiedad Intelectual. Principios básicos del derecho de autor y los derechos conexos. http://www.wipo.int/export/sites/www/freepublications/ es/intproperty/909/wipo_pub_909.pdf

3. Xalabarder, Raquel. "Copyright y derecho de autor: ¿convergencia internacional en un mundo digital?". IDP. Revista de internet, derecho y política, 2005, n. 1, pp. 2-6. http://www.uoc.edu/idp/1/dt/esp/monografico.pdf

4. Loredo A., Alejandro. "Derecho comparado: derecho de autor y copyright. Dos caminos que se encuentran". AR: Revista de derecho informático, 2006, n. 91.

http://www.alfa-redi.org/rdi-articulo.shtml?x=4700

5. Convenio de Berna para la protección de las obras literarias y artísticas.

http://www.wipo.int/treaties/es/

6. Convención de Roma sobre la protección de los artistas intérpretes o ejecutantes, los productores de fonogramas y los organismos de radiodifusión.

http://www.wipo.int/treaties/es/

7. Organización Mundial de la Propiedad Intelectual (OMPI) WIPO) http://www.wipo.int/

8. Directiva 93/83/CEE del Parlamento Europeo y del Consejo, de 27 de septiembre de 1993.

9. Agencia EFE. "Un compositor pide 50 millones a la SGAE por una canción dedicada a Iniesta". El periódico, 2010, agosto.

http://www.elperiodico.com/es/noticias/sociedad/20100804/ compositor-pide-millones-sgae-por-una-cancion-dedicadainiesta/420922.shtml

10. Méndez, Rafael. "Un juez niega que la SGAE pueda cobrar por toda la música". El país, 2007, mayo.

http://www.elpais.com/articulo/cultura/juez/niega/SGAE/ pueda/cobrar/toda/ musica/elpepuint/20070520elpepicul_ 4/Tes

11. Informe sobre la gestión colectiva de derechos de propiedad intelectual. Comisión Nacional de la Competencia, 2009.

http://www.cncompetencia.es/Administracion/GestionDocu mental/tabid/76/Default.aspx? Entryld=35504\&Command= Core_Download\&Method=attachment

12. Evaluación del sistema de gestión colectiva de los derechos establecidos por la política de propiedad intelectual. Segunda fase. Ministerio de la Presidencia. Agencia Estatal de Evaluación de las Políticas Públicas y la Calidad de los Servicios. Diciembre 2009.

http://www.aeval.es/comun/pdf/evaluaciones/E21-2009. $p d f$

13. Registro de la Propiedad Intelectual. Ministerio de Cultura.

https://wwws.mcu.es/RPIntelectual

14. Electronic Copyright Office. United States Copyright Office.

http://www.copyright.gov/eco/

15. Creative commons

http://creativecommons.org/

16. Licencias Creative commons http://es.creativecommons.org/licencia/

17. Memorandum on Creative commons licenses. Association Littéraire et Artistique Internationale (ALAI). Enero 2006.

http://www.alai-usa.org/recent_developments.htm

18. Zachary Katz. "Pitfalls of open licensing: an analysis of Creative commons licensing". IDEA, 2006, v. 46, n. 3, pp. 391-413.

19. Creative commons plus http://wiki.creativecommons.org/CCPlus

20. Getty Images

http://www.gettyimages.com/

21. Image Stamper http://www.imagestamper.com/

22. Safe creative http://www.safecreative.org/

23. Licencias GNU http://www.gnu.org/licenses/ 


\section{MiBib]jotect}

Actualidad bibliotecaria

Fotografía momentos de lectura

Opinión

Recomendaciones de lectura Escolares

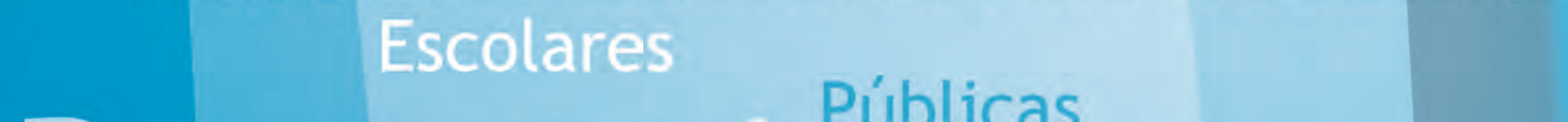

Reportaje Públicas Recursos Universitarias

Con pasado

Cartas a Mi B Bibliotecarios
Con futuro

Noticias Agenda délor

Gestión documental

www.mibiblioteca.org 